\title{
Chromosomal and oxidative DNA damage in non-functioning pituitary adenomas
}

\author{
Nazmiye Bitgen', Fahri Bayram², Zuhal Hamurcu', Figen Ozturk³, Yasin Simsek², Gulden Baskol', \\ Ali Kurtsoy ${ }^{5}$, Hamiyet Donmez-Altuntas ${ }^{1}$
}

${ }^{1}$ Department of Medical Biology, Faculty of Medicine, Erciyes University, Kayseri, Turkey

${ }^{2}$ Department of Endocrinology and Metabolism, Faculty of Medicine, Erciyes University, Kayseri, Turkey

${ }^{3}$ Department of Pathology, Faculty of Medicine, Erciyes University, Kayseri, Turkey

${ }^{4}$ Department of Biochemistry, Faculty of Medicine, Erciyes University, Kayseri, Turkey

${ }^{5}$ Department of Brain Surgery, Faculty of Medicine, Erciyes University, Kayseri, Turkey

\begin{abstract}
Introduction: Clinically non-functioning pituitary adenomas (NFPA) are common tumours of the pituitary gland and are mainly considered as benign. The primary aim of this study was to research the effects of NFPA on genome instability in patients with non-functioning pituitary adenoma by using the cytokinesis-block micronucleus cytome (CBMN-cyt) assay and 8-hydroxy-2'-deoxyguanosine (8-OHdG) assay. The second objective of this study was to assess whether there is a relationship between age, pituitary adenoma diameters, 8 -OHdG levels, CBMN site assay parameters, and tumour aggressiveness.

Material and methods: The study was performed on 30 patients who had been diagnosed with NFPA and were admitted to the Department of Endocrinology and Metabolism, and 20 healthy subjects of similar age and sex.

Results: Micronucleus (MN), nucleoplasmic bridges (NPBs), nuclear bud (NBUD) frequencies, and apoptotic and necrotic cell frequencies in patients with NFPA were found to be significantly higher than in control subjects, and plasma 8-OHdG levels in patients with NFPA were statistically significantly lower than control subjects in this study.

Conclusions: It is believed that this is the first study to evaluate the aggressiveness of tumour with chromosome/oxidative DNA damage in patients with NFPA. However, further studies are needed in order to understand the cause of NFPA aggression and to evaluate these patients in terms of risk of cancer. (Endokrynol Pol 2021; 72 (2): 97-103)
\end{abstract}

Key words: 8-OHdG levels; DNA damage; micronucleus; non-functioning pituitary adenoma

\section{Introduction}

Pituitary adenoma is a common disease that occurs in the pituitary gland and is clinically categorised as functioning and non-functioning pituitary adenomas (FPA and NFPA) [1-5]. Clinically compared to FPA, NFPA does not secrete active hormones and is not associated with clinical syndromes, for example acromegalic features, amenorrhoea-galactorrhoea, or hyperthyroidism. The vast majority of clinical NFPAs secrete gonadotropins, and it is generally known that they are gonadotroph pituitary adenomas [6]. The plurihormonality of pituitary adenomas can be defined as the ability to express more than one pituitary hormone [7]. The prevalence of NFPA is $15-30 \%$ of pituitary adenomas, and the annual incidence is 1 new case per 100,000 of the population [6, 8-11]. Small non-functioning tumours are generally asymptomatic, but most of them are macroadenomas (measuring more than $1 \mathrm{~cm}$ in size at the time of diag- nosis). Most of non-functioning adenomas may be clinically more rapid in terms of invasiveness, recurrence, and aggressiveness, although it is usually histopathologically benign. When these tumours enlarge, they may compress surrounding structures and commonly cause a variety of symptoms, such as hypopituitarism, headache, and visual field defects [12, 13]. NFPAs are usually diagnosed by magnetic resonance imaging (MRI), hormone test, and vision test [14, 15]. NFPAs are more common in men and postmenopausal women [16].

The cytokinesis-block micronucleus cytome (CBMN-cyt) assay is comprehensive technique for measuring DNA damage, cytostasis, and cytotoxicity in cultured human lymphocytes. The events of DNA damage are scored specially in once-divided binucleated cells. These events include the following: micronucleus (MN), as a biomarker of chromosome breakage and/or loss; nucleoplasmic bridges (NPBs), as a biomarker of DNA misrepair and/or telomere end-fusions; and 
nuclear buds (NBUDs), as a biomarker of elimination of amplified DNA and/or DNA repair complexes. In addition, cytostatic effects are measured via the proportion of mono-, bi-, and multinucleated cells - this method also allows the measurement of cytotoxicity via necrotic and/or apoptotic cell ratios [17-20].

Oxidative stress plays an important role in the development of various diseases and is known to cause DNA damage involving point mutations because of base oxidation, single and double strand breaks, and/or genomic instability. 8-hydroxy-2'-deoxyguanosine (8-OHdG) is one of the predominant forms of damaged DNA products due to free radical-induced oxidative lesions, and it can be detected in various biological samples such as urine, cell culture, serum, and plasma. An increased level of 8-OHdG is widely used as an established marker of oxidative stress and cancer [21-23]. There is some literature on oxidative and chromosomal DNA damage in other pituitary adenomas, especially in GH-secreting and prolactin-secreting adenomas [24-26].

On the other hand, we have not found a report in the literature on oxidative and chromosomal DNA damage in patients with NFPA. For this reason, we assessed the frequencies of MN, NPBs, NBUDs, necrotic and apoptotic cells, and nuclear division index (NDI) using the CBMN-cyt assay and oxidative DNA damage using the 8-OHdG assay, in patients with non-functioning pituitary adenoma. The relations among age, pituitary adenoma diameters, 8-OHdG levels, and CBMN-Cyt assay parameters were also examined. Thus, $8-\mathrm{OHdG}$ levels and CBMN-Cyt assay parameters may used as novel biomarkers for early detection of aggressive or invasive pituitary tumours.

\section{Material and methods}

\section{Patients and controls}

The study was performed in 30 patients who had been diagnosed with NFPA and were admitted to the Department of Endocrinology and Metabolism at Erciyes University Medical Faculty from December 2011 to August 2013. Twenty age- and sex-matched healthy controls were also included in the study.

All patients included in the study were recorded with name, surname, file number, age, sex, place of residence, telephone number, complaints on arrival, basal pituitary hormone values before surgery, magnetic resonance (MR) imaging results, and postoperative pathology reports.

The diagnosis of NFPA was made based on clinical and biochemical findings. At diagnosis, the majority of these patients with NFPA had macroadenoma, visual field defects, and at least growth deficiency and hypogonadism. Additionally, a magnetic resonance imaging (MRI) scan of the pituitary gland was used to detect, locate, and determine the size of adenomas. Patients with NFPA were diagnosed with complaints, and underwent a physical examination and pituitary MRI. A non-functioning adenoma was diagnosed in patients with a pituitary adenoma and no hormonal excess. All patients with NFPA were assessed by the same endocrinologist (FB). The patients in the study included 13 females and 17 males, 22-72 years old. All patients included in the study had been newly di- agnosed and had not received any medical or surgical therapy for NFPA. Twenty-nine of the patients had macroadenoma (96.67\%) and only one had microadenoma (3.33\%). The control group was selected from healthy subjects matched for age, gender, and socioeconomic status. None of the participants were taking medications for medical or other reasons, or had diseases such as hypertension, diabetes mellitus, heart disease, or cancer. A standardised questionnaire was designed to obtain relevant details of their current health status, history, and lifestyle, and to collect information on past medical history, drug, and smoking habits. The study excluded patients and controls subjects who reported consumption of alcohol or more than three cups/day of tea and/or coffee, and subjects who had a history of occupational and environmental exposure to known genotoxic chemicals.

The local Ethics Committee approved the study protocol, and all patients provided written informed consent. The study was conducted in accordance with the Declaration of Helsinki and local laws.

\section{Measurement of basal pituitary hormones}

The basal pituitary hormones and necessary peripheral hormones were examined in pre-operative follow-ups of the patients.

Blood samples were obtained from patients for the measurement of growth hormone (GH), insulin-like growth factor 1 (IGF-1), follicle-stimulating hormone (FSH), luteinising hormone (LH), total testosterone (tT), free testosterone (fT), free thyroxine (fT4), free tri-iodothyronine (fT3), prolactin (PRL), oestradiol (e2), adrenocorticotropic hormone $(\mathrm{ACTH})$, thyroid-stimulating hormone (TSH), and cortisol. All serum samples were collected early in the morning after fasting for 8-10 $\mathrm{h}$.

Basal hormone levels were measured using radioimmunoassay (RIA), immunoradiometric assay (IRMA), or chemiluminescence assay at the Erciyes University Medical Faculty Biochemistry Laboratory.

\section{Immunohistochemical evaluation}

The operation material was sent to the Erciyes University Medical Faculty pathology laboratory for those who underwent surgery among the patients included in the study. The tissues were kept in $10 \%$ formaldehyde for 24 hours, and then tissues were taken for follow-up. Cross-sections of 0.4 microns were made in the paraffinembedded tissues. These sections were stained with haematoxylin and eosin and evaluated on a microscope. PRL, TSH, GH, ACTH, FSH, and LH paints were applied to each case. All of the cases were evaluated as NFPA with pathologic result and radiographic changes. According to immunohistochemical results, $\mathrm{LH}$ - and FSHpositive staining appeared in $17(5 \mathrm{LH}, 1 \mathrm{FSH}, 11 \mathrm{FSH}$ and $\mathrm{LH}$ positive) patients with NFPAs, while in 13 patients with NFPAs null-cell adenomas were seen. All immunohistochemical examinations and pathologic evaluations were performed by the same pathologist.

\section{Radiological evaluation}

Three-dimensional volumetric pituitary MR imaging was performed in pre-operative follow-up to patients at the Department of Radiology at Erciyes University (Philips Gyroscan Intera 1.5 Tesla; 35 Best, Netherlands). The evaluation and reporting of the MRs was done by the Radiology Department of the Medical Faculty of Erciyes University.

\section{Whole-blood cultures of human lymphocytes}

After written informed consent had been obtained, the heparinised blood samples $(3 \mathrm{~mL})$ were obtained from all patients and controls. Approximately $0.4 \mathrm{~mL}$ of heparinised whole blood samples were cultured in $5 \mathrm{~mL}$ of culture medium (peripheral blood karyotyping medium) with $1.5 \%$ phytohaemagglutinin-M (PHA-M) to stimulate T-lymphocytes in a $37^{\circ} \mathrm{C}$ incubator for $72 \mathrm{~h}$ (all materials from Biological Industries, Kibbutz Beit Haemek, Israel). Duplicate cultures were made for each patient and control subject, to determine intraindividual differences [27] 


\section{CBMN-Cyt assay}

CBMN-Cyt assay was performed according to some modifications of the protocol described by Fenech in 2000 and 2007 [18, 28]. Cells were blocked with cytochalasin-B (Sigma-Aldrich, St. Louis, Mo.) at a final concentration of $3 \mathrm{mcg} / \mathrm{mL}$ to each culture tube, after 44 hours of incubation to block cytokinesis. The cultures were stopped at $72 \mathrm{~h}$ of incubation, treated with hypotonic solution $(0.1 \mathrm{M} \mathrm{KCl})$ for $4 \mathrm{~min}$ and fixed with two changes of methanol:acetic acid (3:1) [18, 29]. To prepare the slides, the fixed cells were dropped ( $7-8$ drops) onto glass slides and air-dried. The slides were stained for $10 \mathrm{~min}$ with 5\% Giemsa (Merck KGaA, Darmstadt, Germany) in Sorensen buffer. To determine the intra-individual differences, the different slides of two parallel cultures for each patient and control subject were prepared and evaluated. All slides were scored under a light microscope (Nikon Alphaphot-2 YS2-H, Inc., Tokyo, Japan) with a $40 \times 10$ magnification, and CBMN-cyt assay parameters such as MN, NBUDs, and NPBs were additionally verified under $1000 \times$ magnification. For each slide obtained from each duplicate culture, the score was obtained with two different scores with an identical microscope.

The number of mono-, bi-, tri-, and tetra-nucleated cells per 1000 viable mono-nucleated cells was scored in peripheral blood lymphocytes of all individuals to determine cytostatic effects. NDI was calculated using the following formula:

$$
N D I=(M 1+2 M 2+3 M 3+4 M 4) / N,
$$

where M1-M4 are the numbers of cells with 1-4 nuclei and N is the total number of viable cells scored, excluding necrotic and apoptotic cells $[18,30]$.

\section{Determination of 8-OHdG levels}

Two-millilitre heparinised blood samples taken from the patients were immediately centrifuged at room temperature for 15 minutes at $1512 \times \mathrm{g}$ for analysis of 8-OHdG. The plasma was stored in microtubes at $-80^{\circ} \mathrm{C}$ until it was analysed. Plasma 8-OHdG levels were measured using an ELISA kit (NWK-8-OHdG02; Northwest Life Science Specialties, LLC, Vancouver, WA), and the intra-assay coefficient of $8-\mathrm{OHdG}$ assay was calculated to be $5.9 \%$. Plasma 8-OHdG levels were expressed in $\mathrm{ng} / \mathrm{ml}$. Calibration, curve fitting, and data analysis were performed according to the manufacturer's instructions.

\section{Statistical analyses}

The data were analysed using the SPSS for Windows statistical package, version 15.0. The non-parametric Mann-Whitney U test was used to test the differences in CBMN-Cyt assay parameters and 8-OHdG levels between patients with NFPA and control subjects. Spearman's rho correlation analysis was used to assess the relation between age, pituitary adenoma diameter, 8-OHdG level, and CBMN-Cyt assay parameters. Differences were considered statistically significant when $\mathrm{p}$ values were less then 0.05 .

\section{Results}

Table 1 shows the results for age, adenoma diameter, CBMN-cyt assay parameters, and 8-OHdG level for 30 patients with NFPA and 20 control subjects.

Table 2 shows Spearman's rho correlation coefficients and significance for age and pituitary adenoma diameters for patients with NFPA and control subjects.

\section{DNA damage in peripheral blood lymphocytes}

Micronucleus, NPB, and NBUD frequencies in patients with NFPA were found to be significantly higher than those in control subjects $(\mathrm{p}<0.001, \mathrm{p}<0.001$, and $\mathrm{p}<0.001$, respectively) (Tab. 1 and Fig. 1). No correlation was found between age and pituitary adenoma size and DNA damage parameters (MN, NPB, and NBUD frequencies) in patients with NFPA and control subjects (p > 0.05, Tab. 2).

\section{Cytotoxicity in peripheral blood lymphocytes}

Apoptotic and necrotic cell frequencies in patients with NFPA were found to be significantly higher than in control subjects $(\mathrm{p}<0.001$ and $\mathrm{p}<0.005$, respectively, Tab. 1 and Fig. 2). There was a negative correlation between pituitary adenoma size and apoptotic and necrotic cell frequency in patients with NFPA ( $\mathrm{p}<0.05, \mathrm{r}:-0.387$, r: -0.408 , respectively, Tab. 2).

\section{Cytostasis in peripheral blood lymphocytes}

The NDI values of patients with NFPA were found to be significantly higher than the control subjects $(\mathrm{p}<0.001$,

Table 1. Results of CBMN-Cyt assay parameters and 8-OHdG levels in patients with non-functioning pituitary adenomas (NFPA) and control subjects (mean $\pm S D$ )

\begin{tabular}{|c|c|c|c|}
\hline & $\begin{array}{l}\text { Patients with NFPA } \\
\qquad(\mathrm{n}=30)\end{array}$ & $\begin{array}{l}\text { Control subjects } \\
\qquad(n=20)\end{array}$ & p value \\
\hline Age [yrs] & $53.00 \pm 13.39$ & $48.95 \pm 13.84$ & 0.29 \\
\hline Adenoma diameters [mm] & $26.83 \pm 10.32$ & - & - \\
\hline MN frequency (\%) & $1.82 \pm 0.66$ & $0.73 \pm 0.32$ & $<0.001$ \\
\hline NPB frequency (\%) & $5.66 \pm 3.04$ & $2.01 \pm 0.93$ & $<0.001$ \\
\hline NBUD frequency (\%) & $2.83 \pm 1.13$ & $0.93 \pm 0.46$ & $<0.001$ \\
\hline Frequency of apoptotic cells (\%) & $5.70 \pm 3.52$ & $1.30 \pm 0.81$ & $<0.001$ \\
\hline Frequency of necrotic cells (\%) & $5.09 \pm 3.05$ & $2.86 \pm 1.08$ & $<0.005$ \\
\hline NDI & $1.29 \pm 0.79$ & $1.20 \pm 0.87$ & $<0.001$ \\
\hline 8-OHdG levels (ng/mL) & $0.43 \pm 0.32$ & $0.64 \pm 0.18$ & $<0.001$ \\
\hline
\end{tabular}

MN — micronucleus; NBUD — nuclear bud; NPB — nucleoplasmic bridge; NDI — nuclear division index; 8-0hdG — 8-hydroxy-2'-deoxyguanosine 
Table 2. Spearman's rho correlation coefficients and significance values for age and pituitary adenoma diameters with CBMN-Cyt assay parameters and 8-hydroxy-2'-deoxyguanosine (8-OhdG) levels in patients with non-functioning pituitary adenoma and control subjects

\begin{tabular}{|c|c|c|c|c|c|c|c|}
\hline & $\begin{array}{c}\text { MN } \\
\text { frequency (\%) }\end{array}$ & $\begin{array}{c}\text { NPB } \\
\text { frequency }(\%)\end{array}$ & $\begin{array}{c}\text { NBUD } \\
\text { frequency (\%) }\end{array}$ & $\begin{array}{c}\text { Frequency } \\
\text { of apoptotic } \\
\text { cells }(\%)\end{array}$ & $\begin{array}{c}\text { Frequency of } \\
\text { necrotic cells } \\
(\%)\end{array}$ & NDI & $\begin{array}{l}\text { 8-0HdG levels } \\
{[\mathrm{ng} / \mathrm{mL}]}\end{array}$ \\
\hline \multicolumn{8}{|c|}{ Patients with non-functioning pituitary adenoma $(n=30)$} \\
\hline \multicolumn{8}{|c|}{ Age [yrs] } \\
\hline r & -0.133 & 0.103 & 0.161 & -0.054 & 0.011 & -0.176 & 0.065 \\
\hline $\mathrm{p}$ & 0.482 & 0.590 & 0.396 & 0.776 & 0.954 & 0.352 & 0.732 \\
\hline \multicolumn{8}{|c|}{$\begin{array}{l}\text { Pituitary adenoma } \\
\text { diameters [mm] }\end{array}$} \\
\hline $\mathrm{r}$ & -0.202 & -0.280 & -0.236 & $-0.387^{*}$ & $-0.408^{*}$ & -0.110 & -0.168 \\
\hline $\mathrm{p}$ & 0.284 & 0.134 & 0.209 & 0.034 & 0.025 & 0.562 & 0.375 \\
\hline \multicolumn{8}{|c|}{ Control subjects $(n=20)$} \\
\hline \multicolumn{8}{|c|}{ Age [yrs] } \\
\hline r & 0.160 & 0.134 & 0.406 & 0.020 & -0.272 & -0.296 & 0.002 \\
\hline$p$ & 0.501 & 0.575 & 0.075 & 0.935 & 0.246 & 0.205 & 0.995 \\
\hline
\end{tabular}

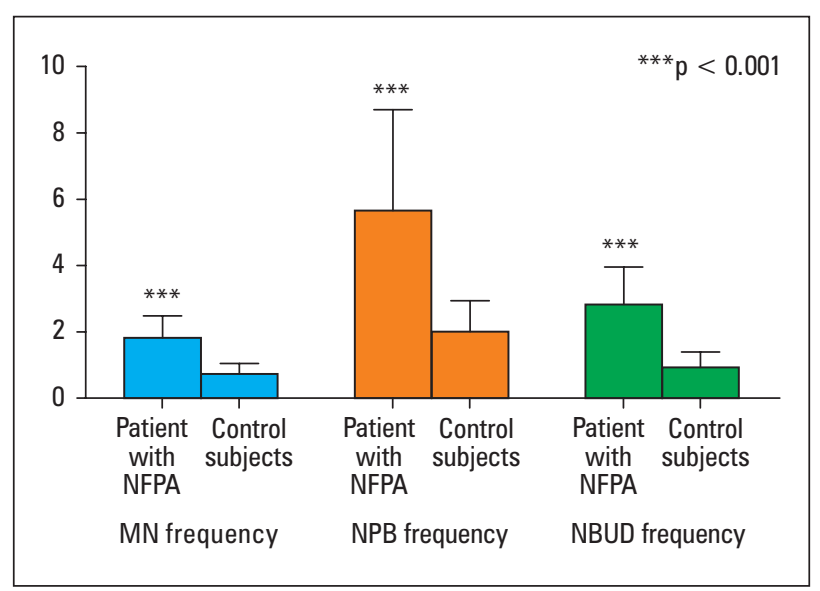

Figure 1. The frequencies of micronucleus (MN), nuclear bud (NBUD), and nucleoplasmic bridge (NPB) in patients with nonfunctioning pituitary adenomas (NFPA) and control subjects

Tab. 1 and Fig. 3). No correlation was found between age and pituitary adenoma size and NDI values in patients with NFPA and control subjects ( $p>0.05$, Tab. 2).

\section{Plasma 8-OHdG levels}

Plasma 8-OHdG levels in patients with NFPA were statistically significantly lower than in control subjects ( $p<0.001$, Tab. 1 and Fig. 4). There was no significant correlation between plasma 8-OHdG levels and age and pituitary adenoma size in patients with NFPA and control subjects ( $\mathrm{p}>0.05$, Tab. 2).

In addition, the MN frequency in patients with non-secreted hormone NFPA was found to be

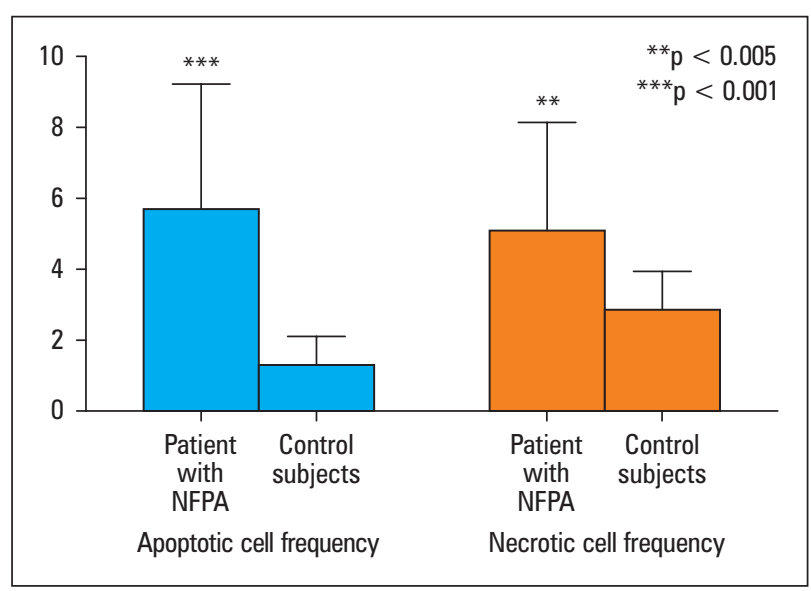

Figure 2. Apoptotic and necrotic cell frequencies in patients with non-functioning pituitary adenomas (NFPA) and control subjects

higher than in patients with secreted hormone NFPA $(\mathrm{p}<0.05)$, while plasma 8-OHdG levels were found to be lower $(\mathrm{p}<0.05)$, from CBMN-cyt assay parameters and plasma 8-OHdG levels in this study.

\section{Discussion}

Clinically, NFPA are common benign tumours, but they are usually large at the time of diagnosis [31, 32]. The main clinical problems that arise in NFPA are hormonal insufficiency due to the effect of pressure on the optic chiasm or the influence of the pituitary hormone-releasing cells due to the mass effect [16]. 


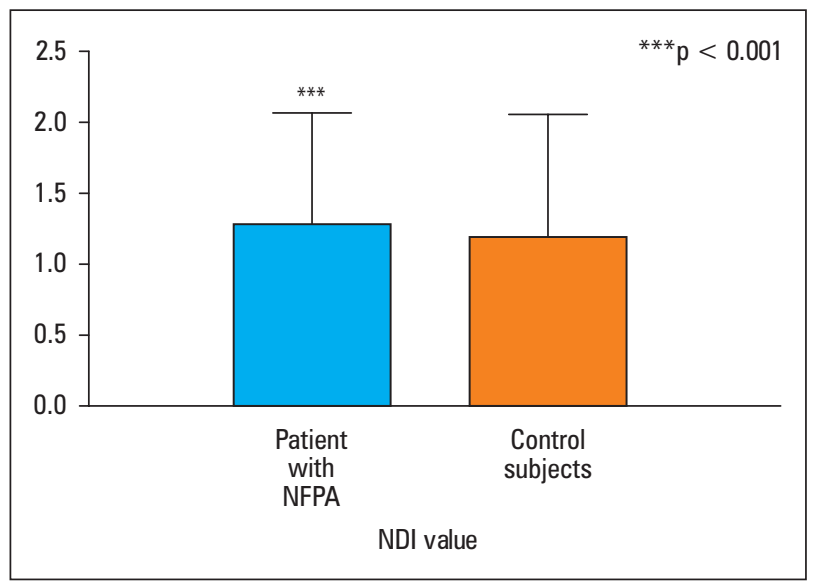

Figure 3. Nuclear division index (NDI) values in patients with non-functioning pituitary adenomas (NFPA) and control subjects

Since there is no overexpression of a specific hormone in non-functioning pituitary adenomas, it is difficult to correlate the increases in the CBMN-Cyt assay parameters (such as frequency of MN, NPBs, and NBUDs) of these patients with any hormone.

NFPA is a very complex all-body disease with multiple molecular dynamic changes in genomic, transcriptomic, proteomic, and metabolomic levels [1, 33-36]. The increase in DNA damage parameters (MN, $\mathrm{NPB}$, and NBUD frequencies) in patients with NFPA in our study may be associated with multiple molecular dynamic alterations in these patients.

In our study, 8-OHdG levels in patients with NFPA were significantly lower than control subjects. Base damage that occurs in DNA is repaired by a base excision repair mechanism. Errors that occur during this repair mechanism cause an increase in DNA chain breaks. Therefore, we believe that oxidative DNA damage occurs in these patients and that some of these damages may be repaired. But faults during repair of chromosomal DNA damage may also contribute to the increase in MN, NPB, and NBUD frequencies. According to literature reviews, there has been no study of plasma 8-OHdG levels in these patients before, and these results need to be supported by further studies.

Apoptotic and necrotic cell frequencies were significantly higher in patients with NFPA than in control subjects. However, despite this increase in cytotoxicity in patients with NFPA, the NDI ratio was found to be increased compared to control subjects. An increase in cell death due to increased genomic instability is an expected condition. We can assume that these DNA damages seen in NFPA are repaired in accordance with the increase of NDI ratio and that the cells continue to multiply and not die.

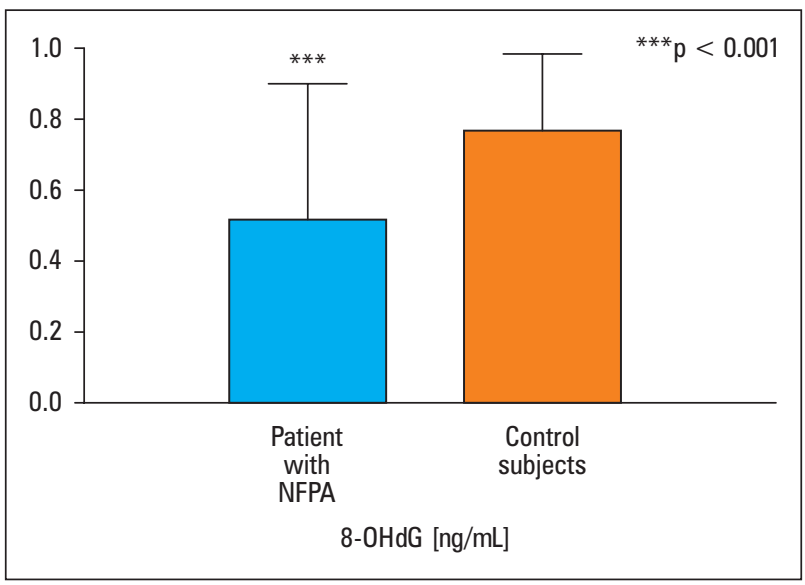

Figure 4. Plasma 8-hydroxy-2'-deoxyguanosine (8-OHdG) levels in patients with non-functioning pituitary adenomas (NFPA) and control subjects

Increased DNA damage and NDI values and reduced oxidative DNA damage in NFPA may be associated with late diagnosis, and the pituitary adenoma size of these patients is considerably larger than that of other adenomas. Furthermore, because there is no evidence of excessive secretion of a clinically important hormone in non-functioning adenomas, these results may be directly related to the disease, a stimulating growth factor that enlarges the adenoma. However, according to CBMN-Cyt assay parameters, high MN frequencies found in non-secretory patients may be predictable as biomarkers of cancer.

It is unknown why these tumours develop. They are thought to arise from a mutation or mutations in a single pituitary gland cell, but it is unknown why or how this happens. On the other hand, NFPA has a high degree of heterogeneity and difficulties in early diagnosis and treatment. It may be help in the understanding of exploration of variations in molecular mechanisms and discoveries that are effective and reliable biomarkers and therapeutic targets in NFPA.

In the general population, $\mathrm{MN}$ frequency is considered to be a predictor of increased risk of cancer. On the other hand, the formation of nuclear anomalies and/or chromosomal DNA damage parameters including $\mathrm{MN}$, NPBs, and NBUDs are also events that can be seen in the early stages of carcinogenesis [19, 37]. Therefore, increased chromosomal DNA damage parameters in NFPA may be associated with possible cancer risk in these patients. In addition, it has been reported that genomic instability frequently occurs in pituitary tumours [38-43]. However, limited information is available on genomic damage in pituitary adenomas. In our previous studies, we have shown that the MN, NPB, and NBUD frequencies increased in patients with acromegaly and prolactinoma [25-27]. In this study, the increased 
genome damage in patients with NFPA that are not associated with clinical manifestations of pituitary hormone hypersecretion may have contributed to their progression from benign adenomas to malign tumours. Thus, CBMN-Cyt assay parameters including MN, NPB, and NBUD frequencies may be used as novel biomarkers for early detection of aggressiveness and invasion of pituitary tumourigenesis. However, carcinogenesis, such as the development of pituitary adenoma, is also a multi-step and multifactorial process. Further studies are needed in order to understand the cause of NFPA and to evaluate these patients in terms of risk of cancer.

\section{Acknowledgement}

This work was supported by research Projects Units (Project Number: TSD-10-3327).

\section{Funding}

There has been no significant financial support for this work that could have influenced its outcome.

\section{Conflict of interest}

The authors declare that they have no conflict of interest.

\section{Ethics approval}

We further confirm that any aspect of the work covered in this manuscript that has involved either experimental animals or human patients has been conducted with the ethical approval of all relevant bodies and that such approvals are acknowledged within the manuscript. The local Ethics Committee approved the study protocol, and all patients provided written informed consent. The study was conducted in accordance with the Declaration of Helsinki and local laws.

\section{Consent to participate}

We confirm that the manuscript has been read and approved by all named authors and that there are no other persons who satisfied the criteria for authorship but are not listed. We further confirm that the order of authors listed in the manuscript has been approved by all of us.

\section{Consent for publication}

We confirm that we have given due consideration to the protection of intellectual property associated with this work and that there are no impediments to publication, including the timing of publication, with respect to intellectual property. In so doing we confirm that we have followed the regulations of our institutions concerning intellectual property.

\section{Availability of data and material}

Data statements for this study can be accessed from Table 1 and 2 .

\section{Code availability}

No software application or special code can be applied for this study.

\section{Authors' contributions}

All authors contributed to the study. They read and approved the final version of the article.

\section{References}

1. Zhan $X$, Wang $X$, Long $Y$, et al. Heterogeneity analysis of the proteomes in clinically nonfunctional pituitary adenomas. BMC Med Genomics. 2014; 7: 69, doi: 10.1186/s12920-014-0069-6, indexed in Pubmed: 25539738.

2. Zhan X, Long Y. Exploration of Molecular Network Variations in Different Subtypes of Human Non-functional Pituitary Adenomas. Front Endocrinol (Lausanne). 2016; 7: 13, doi: 10.3389/fendo.2016.00013, indexed in Pubmed: 26903949.

3. Wang X, Guo T, Peng F, et al. Proteomic and functional profiles of a follicle-stimulating hormone positive human nonfunctional pituitary adenoma. Electrophoresis. 2015; 36(11-12): 1289-1304, doi: 10.1002/elps.201500006, indexed in Pubmed: 25809007.

4. Karppinen A, Kivipelto L, Vehkavaara S, et al. Transition From Microscopic to Endoscopic Transsphenoidal Surgery for Nonfunctional Pituitary Adenomas. World Neurosurg. 2015; 84(1): 48-57, doi: 10.1016/j. wneu.2015.02.024, indexed in Pubmed: 25731792.

5. Liu X, Ma S, Dai C, et al. Antiproliferative, antiinvasive, and proapoptotic activity of folate receptor -targeted liposomal doxorubicin in nonfunctional pituitary adenoma cells. Endocrinology. 2013; 154(4): 1414-1423, doi: 10.1210/en.2012-2128, indexed in Pubmed: 23462961.

6. Chanson P, Raverot G, Castinetti F, et al. French Endocrinology Society non-functioning pituitary adenoma work-group. Management of clinically non-functioning pituitary adenoma. Ann Endocrinol (Paris). 2015; 76(3): 239-247, doi: 10.1016/j.ando.2015.04.002, indexed in Pubmed: 26072284 .

7. Pawlikowski M, Kunert-Radek J, Radek M. Plurihormonality of pituitary adenomas in light of immunohistochemical studies. Endokrynol Pol. 2010; 61(1): 63-66, indexed in Pubmed: 20205106.

8. Yu Z, Kholova DS, Urmanova YM, et al. Reproductive Function in patients with non-functioning pituitary adenoma according to the register of the republic of Uzbekistan. Int J Biomed. 2016; 6: 133-135, doi: 10.21103/Article6(2)_ShCl.

9. Raappana A, Koivukangas J, Ebeling T, et al. Incidence of pituitary adenomas in Northern Finland in 1992-2007. J Clin Endocrinol Metab. 2010; 95(9): 4268-4275, doi: 10.1210/jc.2010-0537, indexed in Pubmed: 20534753.

10. Daly AF, Rixhon M, Adam C, et al. High prevalence of pituitary adenomas: a cross-sectional study in the province of Liege, Belgium. J Clin Endocrinol Metab. 2006; 91(12): 4769-4775, doi: 10.1210/jc.2006-1668, indexed in Pubmed: 16968795.

11. Fernandez A, Karavitaki N, Wass JAH. Prevalence of pituitary adenomas: a community-based, cross-sectional study in Banbury (Oxfordshire, UK). Clin Endocrinol (Oxf). 2010; 72(3): 377-382, doi: 10.1111/j.1365-2265.200 9.03667.x, indexed in Pubmed: 19650784.

12. Colao A, Di Somma C, Pivonello R, et al. Hormone levels and tumour size response to quinagolide and cabergoline in patients with prolactin-secreting and clinically non-functioning pituitary adenomas: predictive value of pituitary scintigraphy with 123I-methoxybenzamide. Clin Endocrinol (Oxf). 2000; 52(4): 437-445, doi: 10.1046/j.1365-2265.200 0.00951.x, indexed in Pubmed: 10762286.

13. Ferrante E, Ferraroni M, Castrignanò T, et al. Non-functioning pituitary adenoma database: a useful resource to improve the clinical management of pituitary tumors. Eur J Endocrinol. 2006; 155(6): 823-829, doi: 10.1530/eje.1.02298, indexed in Pubmed: 17132751.

14. Jaffe CA. Clinically non-functioning pituitary adenoma. Pituitary. 2006; 9(4): 317-321, doi: 10.1007/s11102-006-0412-9, indexed in Pubmed: 17082898 .

15. Neto LV, Boguszewski CL, Araújo LA, et al. A review on the diagnosis and treatment of patients with clinically nonfunctioning pituitary adenoma by the Neuroendocrinology Department of the Brazilian Society of Endocrinology and Metabolism. Arch Endocrinol Metab. 2016; 60(4): 374-390, doi: 10.1590/2359-3997000000179, indexed in Pubmed: 27533614.

16. Chanson P, Brochier S. Non-functioning pituitary adenomas. J Endocrinol Invest. 2005; 28(11 Suppl International): 93-99, indexed in Pubmed: 16625856

17. Fenech M, Crott J, Turner J, et al. Necrosis, apoptosis, cytostasis and DNA damage in human lymphocytes measured simultaneously within the cytokinesis-block micronucleus assay: description of the method and results for hydrogen peroxide. Mutagenesis. 1999; 14(6): 605-612, doi: 10.1093/mutage/14.6.605, indexed in Pubmed: 10567036. 
18. Fenech M. Cytokinesis-block micronucleus cytome assay. Nat Protoc. 2007 ; 2(5): 1084-1104, doi: 10.1038/nprot.2007.77, indexed in Pubmed: 17546000.

19. Fenech M, Holland N, Zeiger E, et al. The HUMN and HUMNxL international collaboration projects on human micronucleus assays in lymphocytes and buccal cells - past, present and future. Mutagenesis. 2011; 26(1): 239-245, doi: 10.1093/mutage/geq051, indexed in Pubmed: 21164208.

20. Thomas P, Fenech M. Cytokinesis-block micronucleus cytome assay in lymphocytes. Methods Mol Biol. 2011; 682(1): 217-234, doi: 10.1007/97 8-1-60327-409-8 16, indexed in Pubmed: 21057931.

21. Floyd R. The role of 8-hydroxyguanine in carcinogenesis. Carcinogenesis. 1990; 11(9): 1447-1450, doi: 10.1093/carcin/11.9.1447.

22. Chen HI, Liou SH, Ho SF, et al. Oxidative DNA damage estimated by plasma 8-hydroxydeoxyguanosine (8-OHdG): influence of 4, 4'-methylenebis (2-chloroaniline) exposure and smoking. J Occup Health. 2007; 49(5): 389-398 doi: 10.1539/joh 49.389, indexed in Pubmed: 17951971.

23. Valavanidis A, Vlachogianni T, Fiotakis C. 8-hydroxy-2' -deoxyguanosine (8-OHdG): A critical biomarker of oxidative stress and carcinogenesis. J Environ Sci Health C Environ Carcinog Ecotoxicol Rev. 2009; 27(2): 120-139, doi: 10.1080/10590500902885684, indexed in Pubmed: 19412858.

24. Bitgen N, Donmez-Altuntas H, Bayram F, et al. Increased micronucleus, nucleoplasmic bridge, nuclear bud frequency and oxidative DNA damage associated with prolactin levels and pituitary adenoma diameters in patients with prolactinoma. Biotech Histochem. 2016; 91(2): 128-136, do i: 10.3109/10520295.2015.1101163, indexed in Pubmed: 26720589.

25. Bayram F, Bitgen N, Donmez-Altuntas H, et al. Increased genome instability and oxidative DNA damage and their association with IGF-1 levels in patients with active acromegaly. Growth Horm IGF Res. 2014; 24(1): 29-34, doi: 10.1016/j.ghir.2013.12.002, indexed in Pubmed: 24382376.

26. Hamurcu Z, Cakir I, Donmez-Altuntas H, et al. Micronucleus evaluation in mitogen-stimulated lymphocytes of patients with acromegaly. Metabolism. 2011; 60(11): 1620-1626, doi: 10.1016/j.metabol.2011.03.013, indexed in Pubmed: 21550080.

27. Donmez-Altuntas H, Bayram F, Bitgen N, et al. Increased Chromosomal and Oxidative DNA Damage in Patients with Multinodular Goiter and Their Association with Cancer. Int J Endocrinol. 2017; 2017: 2907281, doi: 10.1155/2017/2907281, indexed in Pubmed: 28373882

28. Fenech M. The cytokinesis-block micronucleus technique: a detailed description of the method and its application to genotoxicity studies in human populations. Mutat Res. 1993; 285(1): 35-44, doi: 10.1016/0027-5 107(93)90049-1, indexed in Pubmed: 7678131.

29. Donmez-Altuntas H, Bitgen N. Evaluation of the genotoxicity and cytotoxicity in the general population in Turkey by use of the cytokinesis-block micronucleus cytome assay. Mutat Res. 2012; 748(1-2): 1-7, doi: 10.1016/j.mrgentox.2012.05.013, indexed in Pubmed: 22698568.

30. Eastmond DA, Tucker JD. Identification of aneuploidy-inducing agents using cytokinesis-blocked human lymphocytes and an antikinetochore antibody. Environ Mol Mutagen. 1989; 13(1): 34-43, doi: 10.1002/em.2850130104, indexed in Pubmed: 2783409

31. Olsson DS, Nilsson AG, Bryngelsson IL, et al. Excess Mortality in Women and Young Adults With Nonfunctioning Pituitary Adenoma: A Swedish Nationwide Study. J Clin Endocrinol Metab. 2015; 100(7): 2651-2658, doi: 10.1210/jc.2015-1475, indexed in Pubmed: 25946030.

32. Greenman Y, Stern N, Greenman $Y$, et al. Non-functioning pituitary adenomas. Best Pract Res Clin Endocrinol Metab. 2009; 23(5): 625-638, doi: 10.1016/j.beem.2009.05.005, indexed in Pubmed: 19945027.

33. Zhan X, Desiderio DM. The use of variations in proteomes to predict, prevent, and personalize treatment for clinically nonfunctional pituitary adenomas. EPMA J. 2010; 1(3): 439-459, doi: 10.1007/s13167-010-0028-z, indexed in Pubmed: 23199087.

34. Grech $G$, Zhan $X$, Yoo BC et al. EPMA position paper in cancer: current overview and future perspectives. EPMA J. 2015; 6(1): 9 , doi: 10.1186/s13167-015-0030-6, indexed in Pubmed: 25908947.

35. Hu R, Wang X, Zhan X. Multi-parameter systematic strategies for predictive, preventive and personalised medicine in cancer. EPMA J. 2013; 4(1): 2, doi: 10.1186/1878-5085-4-2, indexed in Pubmed: 23339750.

36. Hood L, Tian Q. Systems approaches to biology and disease enable translational systems medicine. Genom Proteom Bioinf. 2012; 10(4): 181-185, doi: 10.1016/j.gpb.2012.08.004, indexed in Pubmed: 23084773.

37. Bonassi S, Znaor A, Ceppi M, et al. An increased micronucleus frequency in peripheral blood lymphocytes predicts the risk of cancer in humans. Carcinogenesis. 2007; 28(3): 625-631, doi: 10.1093/carcin/bgl177, indexed in Pubmed: 16973674.

38. Chatzellis E, Alexandraki KI, Androulakis II, et al. Aggressive pituitary tumors. Neuroendocrinology. 2015; 101(2): 87-104, doi: 10.1159/000371806, indexed in Pubmed: 25571935

39. Pack SD, Qin LX, Pak E, et al. Common genetic changes in hereditary and sporadic pituitary adenomas detected by comparative genomic hybridization. Genes Chromosomes Cancer. 2005; 43(1): 72-82, doi: 10.1002/gcc.20162, indexed in Pubmed: 15704128.

40. Pack SD, Kirschner LS, Pak E, et al. Genetic and histologic studies of somatomammotropic pituitary tumors in patients with the "complex of spotty skin pigmentation, myxomas, endocrine overactivity and schwannomas" (Carney complex). J Clin Endocrinol Metab. 2000; 85(10): 3860-3865, doi: 10.1210/jcem.85.10.6875, indexed in Pubmed: 11061550.

41. Weil RJ, Vortmeyer AO, Huang S, et al. 11q13 allelic loss in pituitary tumors in patients with multiple endocrine neoplasia syndrome type 1. Clin Cancer Res. 1998; 4(7): 1673-1678, indexed in Pubmed: 9676841.

42. Wierinckx A, Roche M, Raverot G, et al. Integrated genomic profiling identifies loss of chromosome 11p impacting transcriptomic activity in aggressive pituitary PRL tumors. Brain Pathol. 2011; 21(5): 533-543, do : 10.1111/j.1750-3639.2011.00476.x, indexed in Pubmed: 21251114.

43. Lüdecke DK, Beck-Bornholdt HP, Saeger W, et al. Tumour ploidy in DNA histograms of pituitary adenomas. Acta Neurochir (Wien). 1985; 76(1-2): 18-22, doi: 10.1007/BF01403824, indexed in Pubmed: 2988290. 